\section{Systolic Hypertension, Preeclampsia-Related Mortality, and Stroke In California}

We read with interest the provocative article by Judy et al in the June 2019 issue $^{1}$ reporting a series of strokes resulting from accelerated systolic hypertension in women with preeclampsia. Preceding stroke, all patients presented with blood pressure greater than $160 \mathrm{~mm} \mathrm{Hg}$ and classic symptoms such as headache, visual changes, abdominal pain, and nausea. The authors rightly deplore that, "Despite the near-universal occurrence of concerning signs and symptoms, few women in our series received antihypertensive therapy before the occurrence of stroke." We would like to point out that, with regard to stroke prevention or cerebroprotection, not all antihypertensive drug classes are created equal. Given the extremely limited armamentarium of available antihypertensives in pregnancy, a careful therapeutic selection is therefore exceedingly important.

Time and again it has been demonstrated the beta blockers are suboptimal with regard to stroke prevention. This inefficacy may be related to their pseudoantihypertensive effect: blood pressure seems to fall when measured peripherally (upper arm) but remains elevated centrally (aorta and cerebral circulation). ${ }^{2-4}$ Whether beta blockers, because of their pseudo-antihypertensive effect, confer any benefit at all or just provide to the patient and physician a sense of false security is currently hotly debated.

\footnotetext{
Guidelines for Letters. Letters posing a question or challenge to an article appearing in Obstetrics $\mathcal{E}$ Gynecology should be submitted within 8 weeks of the article's publication online. Letters received after 8 weeks will rarely be considered. Letters should not exceed 350 words, including signatures and 5 references. Letters will be published at the discretion of the Editor. The Editor may send the letter to the authors of the original paper so their comments may be published simultaneously. The Editor reserves the right to edit and shorten letters. Letters should be submitted using the Obstetrics \& Gynecology online submission and review system, Editorial Manager (http://ong.edmgr.com).
}

In contrast, long-acting calcium channel blockers (similar to chlorthalidone and indapamide) are agents of choice for stroke prevention, even more efficacious than (pregnancy-contraindicated) blockers of the renin angiotensin cascade. ${ }^{4-6}$ Although there are some data for the calcium channel blockers amlodipine and diltiazem, the data in pregnancy are best for nifedipine, which is also emphasized by most guidelines. Of note, hydralazine is no longer considered a drug of choice because its use is associated with more perinatal adverse effects than other drugs. ${ }^{7}$

As Judy et $\mathrm{al}^{1}$ point out, the pathogenesis of stroke is multifactorial in preeclampsia. Whether therapeutic insight gathered in hypertensive cardiovascular disease outside pregnancy can be extrapolated to patients with preeclampsia remains unknown. Nevertheless, because stroke remains the most devastating maternal complication of preeclampsia, it stands to reason to primarily prevent it with the most efficacious cerebroprotective drug. Clearly, to achieve this goal, long-acting calcium channel blockers are far superior to beta blockers.

Financial Disclosure: Franz H. Messerli received money paid to him from Novartis, Pfizer, Menarini, Lancet, Medscape, Dr. Reddy's Laboratories Ltd., $A C C$, and Medtronic. He also has a relationship with Boehringer. The other authors did not report any potential conflicts of interest.

Franz H. Messerli, MD Luigi Raio, MD

Marc Baumann, MD

Stefano Rimoldi, MD

Emrush Rexhaj, MD

University of Bern Medical School, Bern, Switzerland

\section{REFERENCES}

1. Judy AE, McCain CL, Lawton ES, Morton $\mathrm{CH}$, Main EK, Druzin ML. Systolic hypertension, preeclampsia-related mortality, and stroke in California. Obstet Gynecol 2019;133:1151-9.

2. Williams B, Lacy PS, Thom SM, Cruickshank K, Stanton A, Collier D, et al. Differential impact of blood pressure-lowering drugs on central aortic pressure and clinical outcomes: principal results of the conduit artery function evaluation (CAFE) study. Circulation 2006;113:1213-25.

3. Argulian E, Bangalore S, Messerli FH. Misconceptions and facts about beta- blockers. Am J Med 2019 Feb 25 [Epub ahead of print].

4. Messerli FH, Rimoldi SF, Bangalore S, Bavishi C, Laurent S. When an increase in central systolic pressure overrides the benefits of heart rate lowering. J Am Coll Cardiol 2016;68:754-62.

5. Messerli FH, Staessen JA. Amlodipine better than lisinopril? How one randomized clinical trial ended fallacies from observational studies. Hypertension 2006;48:359-61.

6. Ettehad D, Emdin CA, Kiran A, Anderson SG, Callender T, Emberson J, et al. Blood pressure lowering for prevention of cardiovascular disease and death: a systematic review and meta-analysis. Lancet 2016;387:957-67.

7. Magee LA, Cham C, Waterman EJ, Ohlsson A, von Dadelszen P. Hydralazine for treatment of severe hypertension in pregnancy: meta-analysis. BMJ 2003;327:955-60.

\section{In Reply:}

We thank Dr. Messerli et al for their thought-provoking commentary, which asserts that long-acting calcium channel blockers are superior to beta blockers for the prevention of stroke in patients with preeclampsia. We are not aware of any randomized controlled trials in pregnant women examining this specific issue, and we urge caution in making significant changes to practice based on observations in different patient populations.

The studies referenced by Messerli et al examine nonpregnant populations that are significantly older, with chronic hypertension and other medical comorbidities. ${ }^{1}$ Though it is convenient to extrapolate from the literature on nonpregnant women, this must be resisted. There are significant physiologic changes in pregnancy, including peripheral vasodilation and increases in blood volume and cardiac output. Pharmacokinetic differences are well documented. Longstanding hypertension and medical comorbidities may affect vascular response differently than acute preeclampsia, and preeclampsia itself is known to alter physiology. ${ }^{2}$ It cannot be assumed that findings in a nonpregnant population will be replicated in pregnant women.

Furthermore, stroke is not the only devastating sequelae of preeclampsiaassociated severe hypertension, ${ }^{2,3}$ and the choice of antihypertensive must 